\title{
Type II and type IV topoisomerase mutations in clinical isolates of Morganella morganii harbouring the qnrD gene
}

\author{
Mariem Nasri Yaiche ${ }^{1,2^{*}}$, Ikbel Denden Rafraf ${ }^{2}$, Qinglan Guo ${ }^{3}$, Maha Mastouri ${ }^{2,4}$, Mahjoub Aouni ${ }^{2}$ \\ and Minggui Wang ${ }^{3}$
}

\begin{abstract}
Introduction: The aim of this study was to show the emergence of the anrD gene among fluoroquinoloneresistant Morganella morganii isolate. The occurrence of mutations in DNA gyrase (gyrA and gyrB) and topoisomerase IV (parC,parE) genes was also investigated in this strain.

Methodology: 95 clinical Enterobacteria were screened for harbouring the gnrD gene. The clinical isolate of $M$. morganii was recovered from urine from a patient hospitalized in the urology unit at Fattouma Bourguiba Hospital, Tunisia. Antibiotic susceptibility was tested with the agar disk diffusion method. Quinolone susceptibility was studied with microbroth dilution technique. The investigations of plasmid mediated quinolone resistance (PMQR) and topoisomerases mutations were performed by polymerase chain reaction and nucleotide sequencing.

Results: This isolate showed high level of resistance to quinolones. The MIC with microbroth dilution technique was $512 \mu \mathrm{g} / \mathrm{ml}$ for norfloxacin, $256 \mu \mathrm{g} / \mathrm{ml}$ for ofloxacin and ciprofloxacin and $64 \mu \mathrm{g} / \mathrm{ml}$ for levofloxacin.

This strain was found to harbour the quinolone resistance determinant qnrD. In addition, this strain harboured two new gyrB mutations (S463A, S464Y) and one parC mutation (S80I).

Conclusions: This is the first report in Tunisia of gnrD determinant and tow new gyrB muations in M. morganii. The nosocomial infection due to this proteeae invites further study of its epidemiologic evolution.
\end{abstract}

Keywords: Morganella morganii, Quinolone resistance, Topoisomerase mutation, anrD

\section{Introduction}

The first qur gene was observed in the late 1990s and described as a plasmid-mediated quinolone resistance gene (PMQR). Since that, five types of $q n r$ genes have been reported: $q n r A$, qnrB, $q n r C, q n r D$, and $q n r S$. Their sequences are deposited at the following website (http://www.lahey. org/qnrStudies/). Most were observed in Enterobacteriaceae, located on large conjugative multi-resistant plasmids, such as pMG252 seen in the original qnrA1-positive strain [1].

The qurD gene was first described in 2009 on a 4270 bp plasmid present in a human clinical isolate of

\footnotetext{
* Correspondence: mariem_nasri@hotmail.com

${ }^{1}$ Faculty of Sciences, Bizerta Carthage University, Bizerta, Tunisia ${ }^{2}$ Laboratory of Biologically Active Substances and Communicable Diseases (LR99ES27), Monastir University, Monastir, Tunisia

Full list of author information is available at the end of the article
}

Salmonella enterica serovar Kentucky and three Salmonella enterica serovar Bovismordificans isolates from China [2]. Since this report, qnrD was found in Escherichia coli [3], M. morganii [4], P. Mirabilis [4,5], Pseudomonas aeruginosa [5] and Providencia rettgeri [6].

We describe the new $\operatorname{gyr} B$ and $\operatorname{parC}$ mutations in a clinical isolate of $M$. morganii harbouring the rare $q n r D$ gene that is first reported in Tunisia.

\section{Material and methods Case presentation}

On 22 November 2012, a 76-years old male presented to the urology department with hematuria and burning micturition that were neglected by the patient since six months. On presentation, he was not febrile with normal vital signs and negative urine culture. 
The ultrasonography shows a bladder of budding aspect, bifocal with long axis $(3 \mathrm{~cm})$. The histopathology revealed urothelial carcinoma infiltrating high-grade bladder (II pTa). On 30/11/2012, underwent a transurethral resection of bladder tumor. A double-current probe $18 \mathrm{c}$ was also introduced.

On 19/01/2013 the patient presented an acute pyelonephritis and the urine culture showed the presence of quinolone resistant $M$. morganii. The empiric antibiotic therapy consisted of three doses a day of 2 g Ampicillin during 4 days. Urine culture subsequently yielded M.morganii. The antibiotic regime was then replaced with three doses a day of cefoxitin 1_g during one week. After this, the urine culture was negative but the haematuria still existed.

\section{Bacterial strain}

M. morganii was isolated from urine and identified using the Vitek 2 identification system (bioMérieux, Marcy l'Etoile, France). The antimicrobial susceptibilities of the M. morganii isolate were determined on Mueller-Hinton agar by the standard disk diffusion procedure as described by the Antibiogram Committee of the French Society for Microbiology (http://www.sfm.asso.fr). The microbroth dilution technique was used to determine the minimal inhibitory concentrations (MIC) for norfloxacin, ofloxacin, ciprofloxacin and levofloxacin.

\section{PMQR screening}

The qnrA, qnrB, qnrS, qnrC, qnrD, aac-Ib, and qepA genes were detected by PCR with the primer sets as described previously [2,7-10].

QnrD primers were used also for the clinical survey of $q n r D$ gene in other quinolone resistance Enterobacteriacae $(\mathrm{n}=95)$ collected from October 2010 to June 2013: Klebsiella pneumoniae $(\mathrm{n}=59)$, Enterobacter cloaceae $(\mathrm{n}=17)$, Citrobacter freundii $(\mathrm{n}=9)$, Salmonella $\operatorname{spp}(\mathrm{n}=6)$, Providencia rettgerii $(\mathrm{n}=3), M$. morganii $(\mathrm{n}=1)$.

\section{Conjugation}

The transferability of $q n r D$ gene between the $M$. morganii isolate and the E. coli $\mathrm{J} 53 \mathrm{Az}^{\mathrm{r}}$ recipient were carried out in LB broth. Cultures of donor and recipient cells in logarithmic phase $(0.5 \mathrm{ml}$ of each) were added to $4 \mathrm{ml}$ of fresh LB broth and incubated overnight without shaking. Transconjugants were selected on Trypticase soy agar (TSA) plates containing sodium azide $(100 \mu \mathrm{g} / \mathrm{ml}$; Sigma Chemical Co., St. Louis, Mo.) for counterselection and gentamicin $(10 \mu \mathrm{g} / \mathrm{ml})$ to select for plasmid-encoded resistance.

\section{Detection of mutations in the topoisomerase II and IV genes}

The quinolone resistance-determinant regions (QRDRs) of $\operatorname{gyr} A, \operatorname{gyr} B, \operatorname{ParC}$ and $\operatorname{parE}$ was amplified as described previously [11]. Products resulting from amplifications were subjected to sequencing. Analysis and comparison of nucleotide and amino acid sequence data were carried out using Lasergene software (version 7.1; DNASTAR, Wisconsin, USA), and programs available from the national Center for Biotechnology Information (http:// www.ncbi.nlm.nih.gov).

\section{Results}

Antibiotic susceptibility of M. morganii

The clinical strain of $M$. morganii showed a low level of resistance to beta-lactams due to its resistance to ampicillin, amoxicillin, ticarcillin and piperacillin only. It was susceptible to amoxicillin/clavulanic acid, ticarcillin/clavulanic acid, piperacillin/tazobactam, cafalotin, cefamandol, cefoxitin, cefotaxim, ceftazidim, cefpirom, aztreonam, imipenem and ertapenem. This strain was resistant to gentamicin and tobramycin but susceptible to amikacin. It showed also, decreased susceptibility to trimethoprime/sulfamides and rifampicin. The MIC with microbroth dilution technique was $512 \mu \mathrm{g} / \mathrm{ml}$ for norfloxacin, $256 \mu \mathrm{g} / \mathrm{ml}$ for ofloxacin and ciprofloxacin and $64 \mu \mathrm{g} / \mathrm{ml}$ for levofloxacin.

\section{Detection of PMQR genes}

The PMQR screening with PCR revealed the presence of $q n r D$ in M.morganii only. None of the other studied Enterobacteria harboured the $q n r D$ gene. The sequencing result showed the presence of $q n r D 1$ in the $M$. morganii isolate. $q n r A, q n r B, q n r S, q n r C$, $a a c-I b-c r$ and $q e p A$ genes were not found in this strain.

\section{Conjugation}

The conjugative reaction fails and the $q n r D$ gene couldn't be transferred to E.coli J53.

\section{Topoisomerase mutations}

Sequencing of PCR products of QRDRs in $\operatorname{gyr} B$ and parC showed two mutations in the QRDR of gyr $B$ at 463 and 464 codons. The first one is an S463A substitution and the second is an S464Y substitution.

Mutation was found also in the QRDR of parC at codon 80. It was an S80I substitution.

\section{Discussion}

The Gram-negative M. morganii is found in the environment and as a part of the normal flora of humans. It has been considered as a rare cause of human infections. However, it is an important opportunistic pathogen in urinary tract, soft tissue infections and also in infections following surgery $[12,13]$. In this case of study, the old age of the patient, the bladder tumor and its resection and the probe introduction after the surgery are risk factors leading to the urinary tract infection with the opportunistic $M$. morganii. 
This $M$. morganii strain was highly resistant to quinolones and $q n r D$ was detected. $q n r D$ was not found to be self transmissible and it could have spread either on a mobilizable plasmid or on a transferable structure integrated into a conjugative plasmid [6]. The transfer of quinolone resistance due to $q n r D$ is always studied on transformants never on transconjugants. In the study of $\mathrm{Hu}$ et al., Proteus mirabilis harbouring $q n r D$ failed to transfer quinolone resistance to E.coli 600 by conjugation [14]. The MIC of ciprofloxacin in E.coli DH10B cells increased in the transformants carring the plasmid pBR322 with the cloned $q n r D$ from $0,002 \mu \mathrm{g} / \mathrm{ml}$ to $0,06 \mu \mathrm{g} / \mathrm{ml}$ (by a factor 32) [2].

However, $q n r D$ positive clinical strains described so far exhibited a high level of quinolone resistance with ciprofloxacin MIC ranging from 1 to higher then $32 \mu \mathrm{g} / \mathrm{ml}$ and they are likely to harbour other quinolone resistance mechanisms $[14,15]$. Topoisomerase mutations have not been always investigated in $q n r \mathrm{D}$ positive clinical strains in order to evaluate how both mechanisms interact. The gyrA and parE primers used to amlify the QRDRs for Enterobacteria were not available for $M$. morganii. The study of Mazzariol A et al. couldn't to amplify gyrA and $\operatorname{par} C$ genes in this bacteria and this is due to its unknown genome [15].

To date, none of $M$. morganii was described with $g y r B$ mutations. In this report, we described for the first time, two new gyrB mutations in $M$. morganii. In gramnegative bacilli, gyrB mutations are rare in clinical strains and they have been described at positions 426 , 431, 447, 463, 464 and 466. The Ser 463Ala mutation has been linked to Klebsiella oxytoca [11].

This is the first report of the previous mutation in $q n r D$ harbouring $M$. morganii. The Ser 464 Phe mutation has been linked to quinolone resistant S.enterica, P.aeruginosa and P.mirabilis [16-18]. In this study, the gyrB Tyr464 mutation was different from those described previously.

For $M$. morganii, the first ParC mutation was reported in the Tunisian study of Mahrouki et al. [19]. It was an S80I mutation associated to the qnrS 1 gene.

Another ParC mutation (S80R) was also described previously in this Proteeae [20]. In this study, we described the first S80I mutation in qnrD-positive $M$. morganii. This type of mutation was already observed in other Enterobacteria but never associated to the $q n r D$ gene [21].

In summary, we have reported for the first time in Tunisia the rare $q n r \mathrm{D}$ in $M$. morganii and also found two new gyrB mutations (S463A and S464Y) and one parC substitution (S80I). In addition to $q n r D$ gene, both mutations in $\operatorname{gyr} B$ and $\mathrm{ParC}$ could contribute to the high level of resistance to quinolones in this strain. The nosocomial infection caused by this bacterium invites further study of its epidemiologic evolution.
Competing interests

The authors declare that they have no competing interests.

\section{Authors'contributions}

MNY carried the bacteria collection and typing antibiotic susceptibility, PCR screening, sequence blasting and writing the manuscript. IDR is project designer and co-supervisor of research work. QG Laboratory supervisor, she controlled the analysis, interpretation of data and controlled the manuscript. MM provided the necessary materials for collection, typing and doing the susceptibility tests. MA project designer and general supervisor of research group. MW General supervisor of research experiments and controlled the manuscript. All authors read and approved the final manuscript.

\section{Author details}

${ }^{1}$ Faculty of Sciences, Bizerta Carthage University, Bizerta, Tunisia. ${ }^{2}$ Laboratory of Biologically Active Substances and Communicable Diseases (LR99ES27), Monastir University, Monastir, Tunisia. ${ }^{3}$ Institute of Antibiotics, Huashan Hospital, Fudan University, Shanghai 200040, China. ${ }^{4}$ Laboratory of Microbiology, Fattouma Bourguiba University Hospital, Monastir, Tunisia.

Received: 25 April 2014 Accepted: 13 July 2014

Published: 9 August 2014

\section{References}

1. Martínez-Martínez L, Pascual A, Jacoby GA: Quinolone resistance from a transferable plasmid. Lancet 1998, 351:797-799.

2. Cavaco LM, Hasman H, Xia S, Aarestrup FM: QnrD, a novel gene conferring transferable quinolone resistance in Salmonella enterica Serovar Kentucky and bovismorbificans strains of human origin. Antimicrob Agents Chemother 2009, 58:603-608.

3. Zhao J, Chen Z, Chen S, Deng Y, Liu Y, Tian W, Huang X, Wu C, Sun Y, Sun Y, Zeng Z, Liu J: Prevalence and dissemination of oqxAB in Escherichia coli isolates from animals, farmworkers, and the environment. Antimicrob Agents Chemother 2010, 54:4219-4224.

4. Koncan R, Mazzariol A, Kocsis B, Fontana R, Lanzafame P, Rassu M, Cornaglia M: First detection in Europe of plasmid-mediated fluoroquinolone resistance qnrD determinant. Clin Microbiol Infect 2010, 16:S126.

5. Ogbolu DO, Daini OA, Ogunledun A, Alli AO, Webber MA: High levels of multidrug resistance in clinical isolates of Gram-negative pathogens from Nigeria. Int J Antimicrob Agents 2011, 37:62-66.

6. Guillard T, Cambau E, Neuwirth C, Nenninger T, Mbadi A, Brasme L, Vernet-Garnier V, Bajolet O, Champsa C: Description of a 2,683-base-pair plasmid containing qnrD in two Providencia rettgeri isolates. Antimicrob Agents Chemother 2011, 56(1):565-568.

7. Cattoir V, Poirel L, Rotimi V, Soussy C, Nordmann P: Multiplex PCR for detection of plasmid-mediated quinolone resistance qnr genes in ESBL-producing enterobacterial isolates. J Antimicrobial Chemother 2007, 60:394-397.

8. Minghua W, Qinglan G, Xiaogang X, Xiaoying W, Xinyu Y, Shi W, Hooper D, Minggui W: New plasmid-mediated Quinolone resistance gene, qnrC, found in a clinical isolate of Proteus mirabilis. Antimicrob Agents Chemother 2009, 53(5):1892-1897.

9. Park C, Robicsek A, Jacoby GA, Sahm D, Hooper D: Prevalence in the United States of $a a c\left(6 \_-l b-c r\right.$ encoding a Ciprofloxacin-modifying enzyme. Antimicrob Agents Chemother 2006, 50(11):3953-3955.

10. Yamane $K$, Wachino J, Suzuki S, Arakawa Y: Plasmid-mediated qepA gene among Escherichia coli clinical isolates from Japan. Antimicrob Agents Chemother 2008, 52(4):1564-1566.

11. Lascols C, Robert J, Cattoir V, Bébéar C, Cavallo J, Podglajen I, Ploy M, Bonnet R, Soussy C, Cambau E: Type II topoisomerase mutations in clinical isolates of Enterobacter cloacae and other enterobacterial species harbouring the qnrA gene. Int J Antimicrob Agents 2007, 29:402-409.

12. Tsai MT, Yeh JT, Yang WC, Wu TH: CAPD-related Peritonitis caused by Morganella morganii. PD 2013, 33:104-105.

13. Chen Y, Peng H, Shia W, Hsu F, Ken C, Tsao Y, Chen C, Liu C, Hsieh M, Chen H, Tang C, Ku T: Whole-genome sequencing and identification of Morganella morganii KT pathogenicity-related genes. BMC Genomics 2012, 13(Suppl 7):S4.

14. Hu Y, Cai J, Zhang R, Zhou H, Sun Q, Chen G: Emergence of Proteus mirabilis harboring blaKPC-2 and $q n r D$ in a Chinese Hospital. Antimicrob Agents Chemother 2012, 56(5):2278-2282. 
15. Mazzariol A, Kocsis B, Koncan R, Kocsis E, Lanzafame P, Cornaglia G: Description and plasmid characterization of $9 n r D$ determinants in Proteus mirabilis and Morganella morganii. Clin Microbiol Infect 2012, 18:E46.

16. Gensberg K, Jin YF, Piddock LJ: A novel gyrB mutation in a fluoroquinolone-resistant clinical isolate of Salmonella typhimurium. FEMS Microbiol Lett 1995, 132:57-60.

17. Mouneimne H, Robert J, Jarlier V, Cambau E: Type II topoisomerase mutations in ciprofloxacin-resistant strains of Pseudomonas aeruginosa. Antimicrob Agents Chemother 1999, 43:62-66.

18. Weigel LM, Anderson GJ, Tenover FC: DNAgyrase and topoisomerase IV mutations associated with fluoroquinolone resistance in Proteus mirabilis. Antimicrob Agents Chemother 2002, 46:2582-2587.

19. Mahrouki S, Bourouis A, Chihi H, Ouertani R, Ferjani M, Moussa MB, Barquellil F, Belhadj O: First characterisation of plasmid-mediated quinolone resistance-qnrS1 co-expressed bla ${ }_{C T X-M-15}$ and bla DHA-1 genes in clinical strain of Morganella morganii recovered from a Tunisian Intensive Care Unit. Indian J Med Microbiol 2012, 30:437-441.

20. Andres P, Lucero C, Soler-Bistué A, Guerriero L, Albornoz E, Tran T, Zorreguieta A, PMQR-Group, Galas M, Corso A, Tolmasky M, Petroni A: Differential distribution of plasmid-mediated Quinolone resistance genes in clinical enterobacteria with unusual phenotypes of Quinolone susceptibility from Argentina. Antimicrob Agents Chemother 2013, 57(6):2467-2475.

21. Lim S, Lim K, Lee H, Jung S, Kang M, Nam H: Prevalence and molecular characterization of Fluoroquinolone-resistant Escherichia coli isolated from diarrheic cattle in Korea. J Vet Med Sci 2010, 72(5):611-614.

doi:10.1186/s12941-014-0034-4

Cite this article as: Nasri Yaiche et al:: Type II and type IV topoisomerase mutations in clinical isolates of Morganella morganii harbouring the qnrD gene. Annals of Clinical Microbiology and Antimicrobials 2014 13:34.

\section{Submit your next manuscript to BioMed Central and take full advantage of:}

- Convenient online submission

- Thorough peer review

- No space constraints or color figure charges

- Immediate publication on acceptance

- Inclusion in PubMed, CAS, Scopus and Google Scholar

- Research which is freely available for redistribution 